\title{
Analysis of Irradiated U-7wt\%Mo Dispersion Fuel Microstructures using Automated Image Processing
}

R. Collette ${ }^{1}$, J. King $^{1, *}$, C. Buesch ${ }^{2}$, D.D. Keiser Jr. ${ }^{3}$, W. Williams ${ }^{3}$, B.D. Miller ${ }^{3}$, J. Schulthess ${ }^{3}$

\begin{abstract}
The High Performance Research Reactor Fuel Development (HPPRFD) program is responsible for developing low enriched uranium (LEU) fuel substitutes for high performance reactors fueled with highly enriched uranium (HEU) that have not yet been converted to LEU. The uranium-molybdenum (U-Mo) fuel system was selected for this effort. In this study, fission gas pore segmentation was performed on U$7 \mathrm{wt} \%$ Mo dispersion fuel samples at three separate fission densities using an automated image processing interface developed in MATLAB. Pore size distributions were attained that showed both expected and unexpected fission gas behavior. In general, it proved challenging to identify any dominant trends when comparing fission bubble data across samples from different fuel plates due to varying compositions and fabrication techniques. The results exhibited fair agreement with the fission density vs. porosity correlation developed by the Russian reactor conversion program.
\end{abstract}

Keywords. nuclear fuel; MATLAB; automated image analysis; fission bubbles; fission density; porosity

\subsection{INTRODUCTION}

The United States Department of Energy's National Nuclear Security Agency (DOENNSA) Office of Material Management and Minimization (M3) is charged with eliminating the use of highly enriched uranium (HEU) to reduce proliferation risks worldwide. The High Performance Research Reactor Fuel Development (HPPRFD) program's primary objective is to develop low enriched uranium (LEU) fuel substitutes for high performance research and test reactors that still use HEU fuel (Wachs, 2007). To be successful, the HPPRFD program must develop a fuel that satisfies all safety and irradiation performance criteria, while also being commercially viable. The uranium-molybdenum (U-Mo) fuel system was selected for this effort primarily for its phase stabilization properties.

\footnotetext{
${ }^{1}$ Colorado School of Mines, Nuclear Science and Engineering Program, 1500 Illinois St, Golden, CO 80401, USA

${ }^{2}$ Oregon State University, 1500 SW Jefferson St., Corvallis, OR 97331, USA

${ }^{3}$ Nuclear Fuels and Materials Division, Idaho National Laboratory, P.O. Box 1625, Idaho Falls, ID 83415-6188, USA

* Corresponding author. Phone: (303) 384-2133, Email: kingjc@ mines.edu
} 
In order to ensure the safe operation of nuclear fuels, it is necessary to be able to predict their behavior during irradiation. An accurate description of a nuclear fuel's behavior involves a multitude of disciplines including chemistry, nuclear and solid state physics, metallurgy, ceramics, and applied mechanics. The strong interrelationship between these disciplines has forced the nuclear industry to develop and rely on fuel performance codes capable of predicting the evolution of irradiated fuel properties. Fuel designers and safety authorities rely heavily on these types of code. The development and validation of these codes are highly reliant on data from in-core irradiation experiments. The primary focus of the research reported in this paper is the development of accurate and efficient image analysis techniques that can be employed to evaluate microstructural characterization data and quantify microstructural features so that there can be a better understanding of fuel performance during irradiation.

More specifically, this study is aimed at gathering information to further understand the behavior of fission products, mainly xenon and krypton, in U-Mo fuel and the growth of fission gas bubbles as they relate to irradiation parameters. For full qualification, a fuel design must exhibit mechanical integrity and predictable swelling during irradiation in order to prevent coolant flow blocks and/or the release of fission products (Meyer et al., 2014). Fission gas bubble nucleation and growth is one of the primary mechanisms contributing to fuel swelling, which increases the mechanical interaction between the fuel and cladding at higher burnups. Significant swelling can eventually lead to total fuel failure. It is therefore essential to be able to measure the presence of fission gas under variable irradiation conditions. In addition, fission gas bubble formation has the potential to be a valuable indicator for assessing the performance limits of a particular fuel design (Keiser et al., 2014). 
Currently, fuel performance evaluators rely on visual inspection or manual segmentation of fuel micrographs to assess most parameters of interest within an irradiated fuel microstructure. Automating this process has the potential to significantly speed up the data extraction process, enhance its consistency, and improve its correctness. Automatic image segmentation of target features can be a valuable tool for providing measurements of features that may be used to increase the fidelity of fuel performance modeling. A previous paper proposed an automated image processing methodology capable of characterizing fission gas bubbles in irradiated U-Mo microstructures (Collette et al., Submitted). This paper will document the data collection using the automated algorithm for five irradiated U-Mo dispersion fuel samples and discuss the results.

\subsection{URANIUM-MOLYBDENUM FUEL}

The two primary fuel forms being developed by the M3 program are U-Mo/Al dispersion fuels and monolithic fuel, both in plate form and containing a U-Mo alloy fuel phase with 7-12\% molybdenum by weight. This focus of this study is solely dispersion type fuel. Plate-type nuclear fuel geometries are often used by research reactors that require a high neutron flux, especially those specializing in isotope production or materials testing. The long, thin nature of the plates enables high in-core uranium loadings and effective heat transfer (Ding et al., 2009). Dispersion fuels consist of atomized U-Mo particles embedded in an aluminum or magnesium matrix (Piro and Leitch, 2014). The fabrication method for the dispersion plates is, first, to blend the uranium feedstock to the correct enrichment, and, second, to blend in the molybdenum to the alloy specification and atomize it into powder. The powder is then mixed with the matrix material powder and pressed into compacts. Finally, the compacts are assembled into aluminum frames and seal-welded between two aluminum cover plates, with the plates then hot rolled to the correct thickness (Perez et al., 2011). The aluminum matrix is frequently enriched with silicon to 
suppress the fuel-matrix interaction layer (FMI) that forms during fuel fabrication and irradiation (Meyer et al., 2014). The FMI phase releases gas fission at the boundary of the aluminum matrix which combine into gas bubbles and have the effect of weakening the fuel meat and exerting internal gas pressure. Eventually, these effects can lead to breakaway swelling and mechanical failure in the form of full plate delamination. As a relatively new fuel type, there are many opportunities for characterization research in which image processing can play a significant role in U-Mo fuel development.

At lower fission densities in U-Mo fuel, fission gas isotopes form along the grain boundaries and precipitate in a face-centered-cubic superlattice of nano-sized bubbles (within the body-centered-cubic U-Mo crystal lattice) in the intragranular regions (Keiser et al., 2014). However, as the fission density increases to around $4.5 \times 10^{21}$ fissions $/ \mathrm{cm}^{3}$, a transition in the microstructure occurs. The U-Mo grains recrystallize into smaller grains, thus increasing the grain boundary density and providing additional defect sites for the formation of fission gas bubbles (Meyer et al., 2014). As fission density increases, the nano-bubble superlattice is destroyed, and micron scale bubbles form along the grain boundaries. High burnup structures exhibit a random fission gas bubble distribution with occasional intact bubble superlattices persisting in residual micron sized fuel grains.

\subsection{FUEL SAMPLING AND IMAGING}

Three uranium 7 wt\% molybdenum (U-7Mo) dispersion fuel mini-plates (R2R040, R3R050, R9R010) were selected for this work that were irradiated in Idaho National Laboratory's (INL) Advanced Test Reactor to fission densities between $5.2 \times 10^{21}$ and $6.3 \times 10^{21}$ fissions $/ \mathrm{cm}^{3}$ (Keiser et al., 2014). The mini-plates are nominally $2.54 \mathrm{~cm}$ wide, $10.16 \mathrm{~cm}$ long and $1.4 \mu \mathrm{m}$ thick. The R2R040 and R3R050 mini-plates were from the RERTR-7 irradiation 
experiment (Perez et al., 2011) while the R9R010 plate was from the RERTR-8 irradiation experiment (Perez et al., 2011). The RERTR-7 experiment was designed to test several modified fuel designs to target fission densities representative of a peak LEU burnup in excess of 90 at\% U-235 at peak experiment power sufficient to generate a peak surface heat flux of approximately $300 \mathrm{~W} / \mathrm{cm}^{2}$ (Perez et al., 2011). The RERTR-7 miniplates used fuel particles that were enriched to 58 wt\% uranium-235. After 89.9 Effective Full Power Days (EFPD), 23.63\% and 24.20\% of the uranium-235 in plates R2R040 and R3R050 was depleted, respectively. The RERTR-8 experiment was designed to test the efficiency of adding magnesium to U-7Mo dispersion fuel particles in order to limit the growth of an interaction layer during irradiation to high burnup and also to test using magnesium as a matrix material to eliminate fuel/matrix interaction. Plate R9R010 (also $58 \mathrm{wt} \%$ enrichment) was the magnesium matrix fuel plate, and it experienced 22.98\% uranium-235 depletion after 58.1 EFPD (Perez et al., 2011).

After the fuel plate activities reached manageable levels due to radioactive decay, approximately $1 \mathrm{~mm}$ by $1 \mathrm{~mm}$ samples were produced using a slow-speed saw at the Hot Fuel Examination Facility and then transferred to the Electron Microscopy Laboratory at INL where they were mounted, polished and milled using a FEI Quanta3D dual-beam focused ion beam (FIB) (Robinson et al., 2009). The FIB is capable of coarse trenching cube lift-outs at specific locations with minimal polishing damage. The cube lift-outs (pictured in Figure 1) used in this study had dimensions of approximately $15 \mu \mathrm{m}$ x $15 \mu \mathrm{m}$ x $15 \mu \mathrm{m}$. After the samples were created, the cubes were mounted on a copper grid and prepared for milling/sectioning. The samples used in this study were sliced in 30 to $55 \mathrm{~nm}$ increments by the FIB at a voltage of $30 \mathrm{kV}$ and a current of 500 pA. Total slice counts range from 100 to 300. A Scanning Electron Microscope (SEM) imaged the samples after each section. Images of each slice were taken at a magnification 
of $10,000 x$, with a default image resolution of $2048 \times 1768$ pixels. Table 1 details the sample labeling as well as thecalculated irradiation parameters for each sample location. Figure 2 demonstrates some of the SEM images produced as the sample C FIB cube was sequentially sliced. The curtaining artifacts created by the FIB milling can be observed in these micrographs.

Table 1: Local calculated irradiation parameters for the high burnup U-7Mo microstructure samples.

\begin{tabular}{|c|c|c|c|c|c|c|c|}
\hline \multirow[b]{2}{*}{ Mini-plate } & \multirow[b]{2}{*}{$\begin{array}{l}\text { FIB Cube } \\
\text { Sample }\end{array}$} & \multirow{2}{*}{$\begin{array}{c}\text { Fission } \\
\text { Density } \\
(\text { fissions } \\
\left./ \mathrm{cm}^{3}\right)\end{array}$} & \multirow{2}{*}{$\begin{array}{c}\text { Average } \\
\text { Fission Rate } \\
\text { Density } \\
\text { (fissions } / \mathrm{cm}^{3} \mathrm{~s} \text { ) }\end{array}$} & \multicolumn{2}{|c|}{$\begin{array}{l}\text { Heat Flux } \\
\left(\mathrm{W} / \mathrm{cm}^{2}\right)\end{array}$} & \multicolumn{2}{|c|}{ Temperature $\left({ }^{\circ} \mathrm{C}\right)$} \\
\hline & & & & BOL* & $\mathrm{EOL}^{* *}$ & BOL* & $\mathrm{EOL}^{* *}$ \\
\hline $\begin{array}{c}\mathrm{Al}-4043 \\
\text { (R3R050) }\end{array}$ & $\begin{array}{l}\mathrm{A} \\
\mathrm{B}\end{array}$ & $5.2 \times 10^{21}$ & $6.6 \times 10^{14}$ & 282 & 245 & 124 & 136 \\
\hline $\begin{array}{c}\mathrm{Mg} \\
\text { (R9R010) } \\
\end{array}$ & $\begin{array}{l}\text { C } \\
\text { D }\end{array}$ & $5.5 \times 10^{21}$ & $11.0 \times 10^{14}$ & 405 & 359 & 145 & 171 \\
\hline $\begin{array}{c}\mathrm{Al}-2 \mathrm{Si} \\
\text { (R2R040) }\end{array}$ & E & $6.3 \times 10^{21}$ & $8.1 \times 10^{14}$ & 337 & 307 & 121 & 119 \\
\hline
\end{tabular}

*Beginning of Life; **End of Life

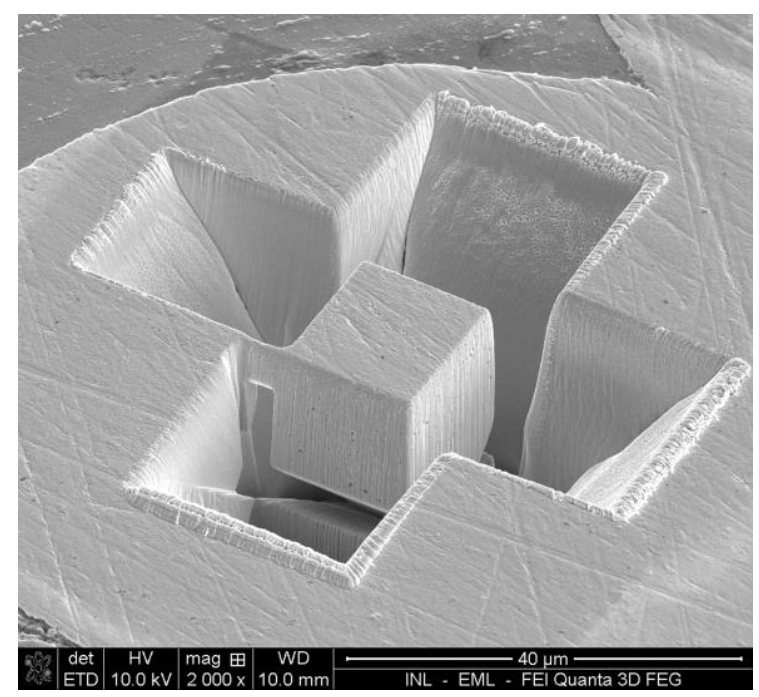

a) Sample lift-out trench created by the FIB.

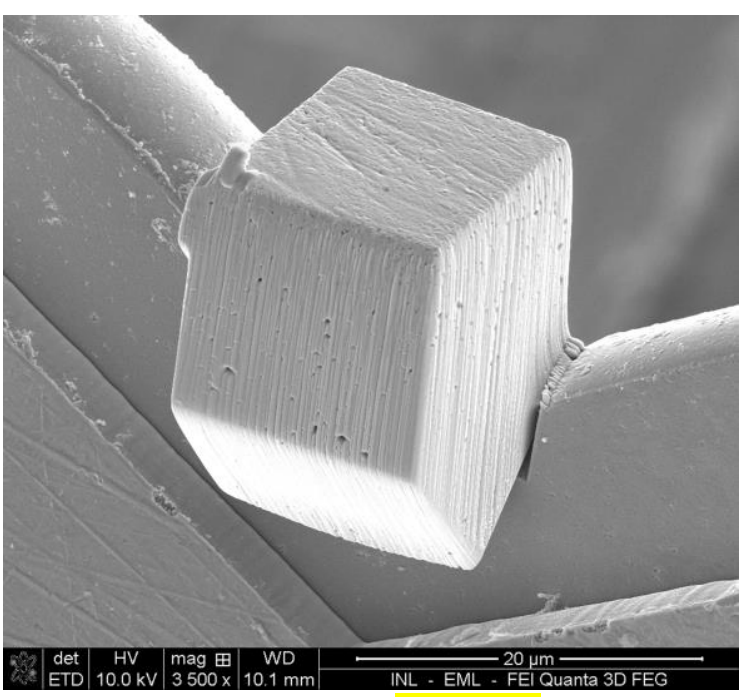

b) Sample mounted and prepared for milling.

Figure 1: Micrographs of the FIB trenching and lift-out process. 


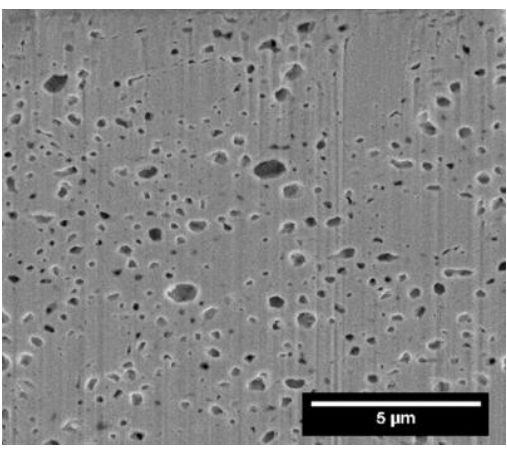

a) Slice 1

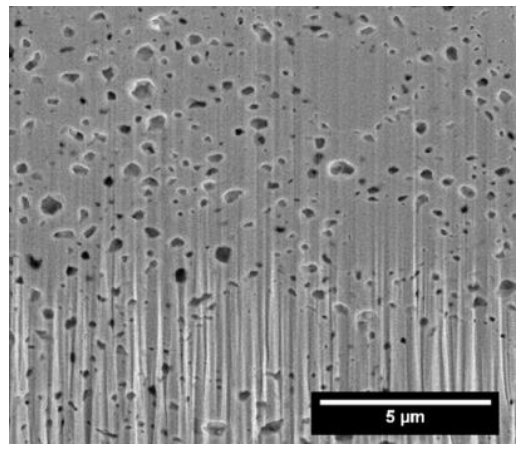

b) Slice 100

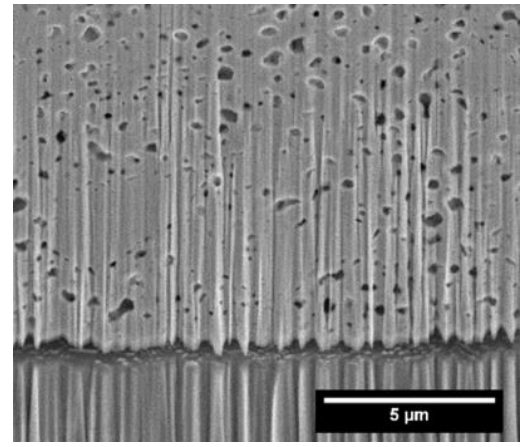

c) Slice 200

Figure 2: Example SEM micrographs from sample D.

\subsection{AUTOMATED IMAGE PROCESSING ALGORITHM}

Scripts designed to characterize gaseous fission products were developed using MATLAB's Image Processing Toolbox (MathWorks, 2014; Collette et al., Submitted). The images in each sample stack were initially run through a frequency domain filtering approach, known as a notch filter, to eliminate the streaking artifacts caused by the FIB milling. This preprocessing step is essential in producing accurate fission gas bubble data, as it significantly enhances the accuracy of the segmentation step (Gonzalez and Woods, 2008). The image stacks were then analyzed by a processing sequence optimized for $10,000 x$ magnification images. The sequence begins by equalizing the histogram to saturate $1 \%$ of the pixels at the low and high

intensities of the image. This enhances the contrast of the image and increases the accuracy of thresholding. The next step in the processing sequence applies a bilateral filter to each image in order to reduce background noise and preserve feature edges (Tomasi and Manduchi, 1998). A Gaussian averaging filter then slightly blurs the image in preparation for thresholding procedures. The Gaussian filter is followed by the Sauvola function, which segments the input image based on histogram weighting factors in stable contrast regions and based on local statistics in variable contrast regions (Sauvola, 2000). After segmentation, a median filter is 
applied to remove any residual stranded pixels. Binary morphology operations then remove any objects touching the image border, fill any holes in objects, and label each individual feature. Data obtained from the feature labels are finally exported to Excel. Figure 3 provides examples of the algorithm output at key steps in the process.

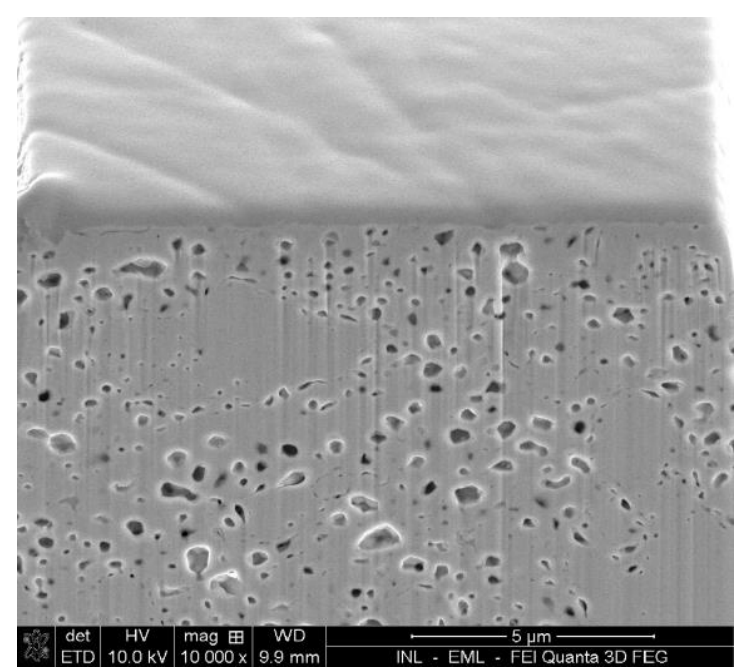

a) Original image.

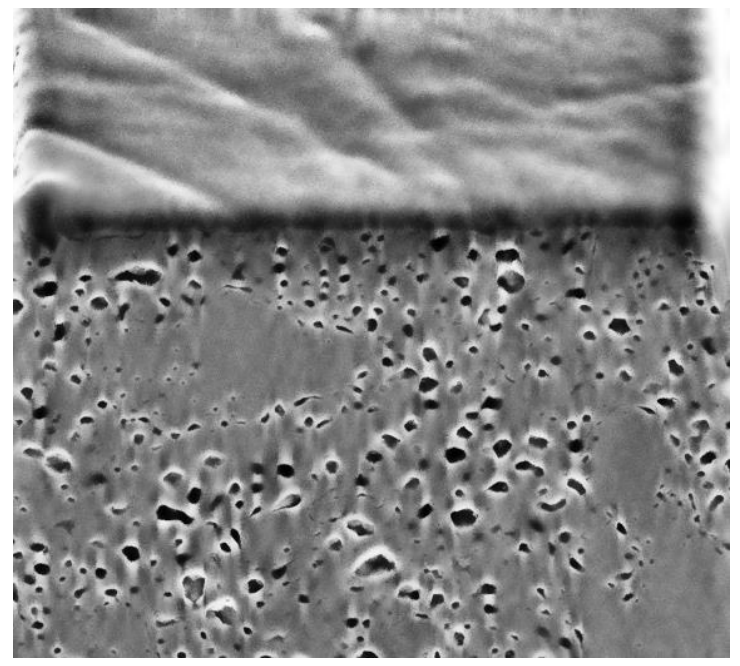

c) Bilateral filtered image.

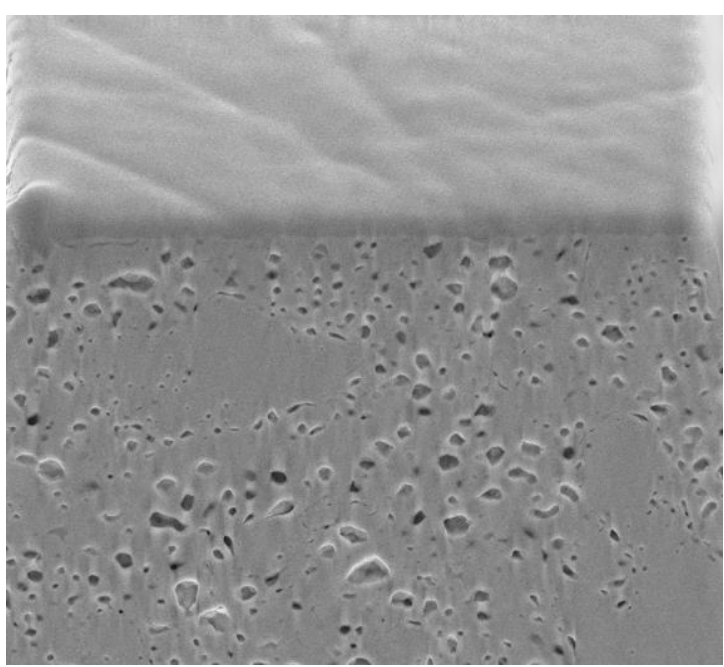

b) Notch filtered image.

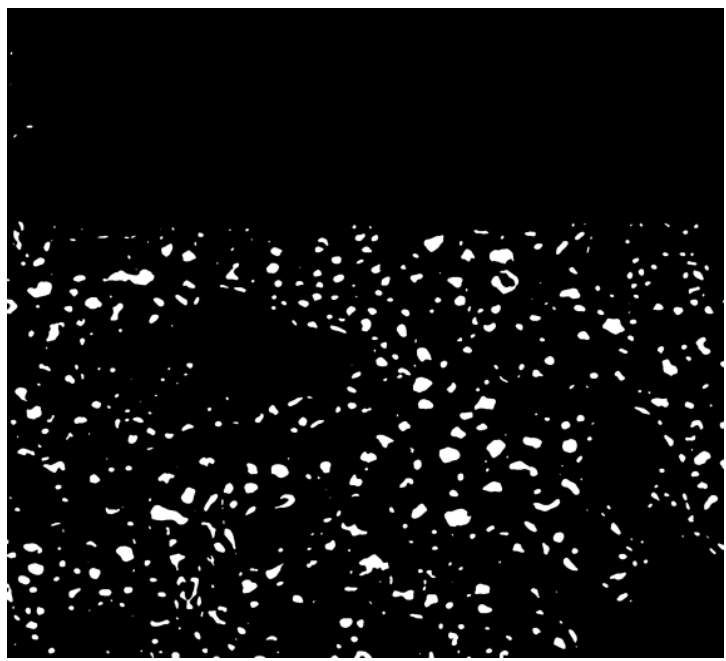

d) Binary segmentation image.

Figure 3: Demonstration of the image processing algorithm on sample D. 


\subsection{VERIFICATION AND VALIDATION}

Before the software algorithm can be transitioned from development to practical application, it must first be subjected to verification and validation. The verification and validation assessment will demonstrate whether the software requirements are correct, complete, consistent, accurate, and testable. This section briefly overviews the testing procedures that were used to validate the automated algorithm result.

Due to the variant nature of U-Mo microstructure samples and a lack of image processing precedent in the nuclear fuels field, a fully characterized reference image does not exist. This means that there is no universally accepted segmentation against which to verify the algorithm's results. The American Society for Testing and Materials (ASTM) develops technical standards to solve these problems. ASTM E 562 is a standard for the determination of volume fraction of a consistent phase in a multi-phase system by systematic manual point count. The standard outlines a methodology for estimating the volume fraction of an identifiable constituent or phase from sections through the microstructure using a point grid. It describes a Monte Carlo method performed by overlaying a grid of points onto a set of microstructure serial sections and tallying the instances in which a grid point overlaps a feature of interest. The number of grid point hits is divided by the total number of grid points, resulting in a rough estimation of porosity for that particular image. This process is repeated using a series of grids until the relative error of the analysis is deemed satisfactory. Though this method is effective, it is tedious, time consuming, and doesn't completely eliminate subjective decision-making (i.e. pore or not pore). It is unrealistic to expect analysts to perform this analysis on hundreds of images. Automating the process is not only significantly faster, but it is more accurate, consistent and testable. In 
addition, the ASTM method only covers porosity. There are a multitude of additional important fission bubble parameters that can only be obtained using image processing.

Sample D was chosen for this test. Twenty-one images at set intervals from image 1 to image 150 had grids constructed and counted in order to reduce the relative error to less than 10\% using a 95\% confidence interval (American Society for Testing and Materials, 2011). A 12 x 14 grid of crosses with spacings roughly twice the size of the average feature size was applied to each image. Crosses that missed, touched the border, or overlapped a fission gas bubble were tallied as $0,0.5$, and 1 , respectively. Table 2 lists details of the ASTM standard test applied to sample D.

Given the results from the porosity test, the next step is to make parameter adjustments to the algorithm until the results fall within the targeted confidence intervals. Given the sensitive nature of the algorithm, a set of parameters that produces the correct results for one image type may not produce the correct results for another. It is left up to the user to make those adjustments between image types as necessary. The results of the ASTM manual point count test produced a confidence interval range between $7.32 \%$ and $8.64 \%$. The image-processing algorithm produced an average porosity of $7.48 \%$ across the 200 images in the sample D stack. Although the true porosity is unknown, it can be reasonably assured, based on these results, that the algorithm produces answers within an acceptable margin of error of the porosity estimated using the ASTM manual point count test.

Table 2: Results of ASTM E562 standard test method for determining volume fraction on sample D.

\begin{tabular}{ll}
\hline Images tested & 21 \\
Grid points & $168(12 \times 14)$ \\
Average porosity & $7.98 \%$ \\
Standard deviation & $1.36 \%$ \\
$95 \%$ Confidence Interval & $7.32 \%-8.64 \%$ \\
Relative Error & $8.30 \%$ \\
\hline
\end{tabular}




\section{IMAGE PROCESSING CONSIDERATIONS}

This section documents the results of data collection for the five samples. The objective of this analysis is to provide a reliable source of data that can be used to compare and contrast between various U-Mo test samples. The samples in this study are extremely small, and as such, they are difficult to compare in a representative manner. In order to extract the most meaningful information from each sample, the image stacks were cropped to particular regions of interest. This was done to ensure the data does not reflect the presence of residual grains or unpolished off-plane regions. These regions may have been present in bordering sections not captured in each sample and must be removed in order to compare samples. Residual grains represent portions of the microstructures that have not yet undergone the transition from a low burnup microstructure to a high burnup microstructure. In these areas, the nanoscale superlattice of fission gas is too small for observation with the SEM. Accordingly, those regions are eliminated from the data analysis so that the porosity calculation remains accurate. In addition, the bubbles surrounding intact grains have morphologies inconsistent with the bulk of bubbles in the recrystallized regions. Grain adjacent fission bubbles appear flattened radially and elongated transverse to the grain, and were therefore mostly eliminated from the dataset. Figure 4 presents an example of this phenomenon.

Since two samples each were taken from both plates R3R050 and R9R010, it is reasonable to assume that samples from the same irradiated plate would have been subjected to similar fission densities. However, it is worth noting that the computer simulations that were used to calculate the fission densities are specific to the plate node, not the fuel kernel that comprises the sample. If the sample was taken from a region with multiple fuel kernels, the 


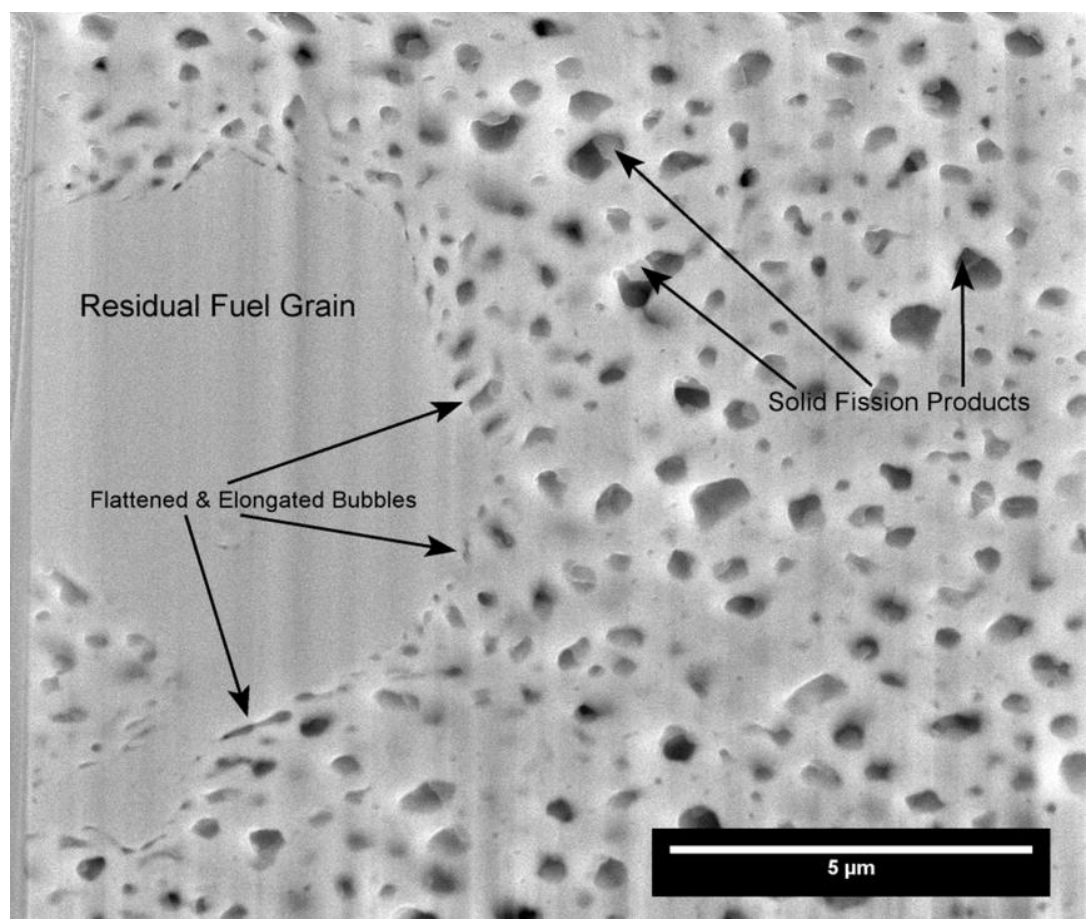

Figure 4: Typical SEM micrograph from plate R3R050 exhibiting a residual fuel grain.

fission density experienced in that location could be significantly higher than the average. The homogeneity of the dispersed fuel particles is an important factor when analyzing the results. That said, if two separate fuel kernels from the same fuel matrix (and thereby the same irradiation conditions) are selected as samples, then their local fission densities should be roughly equivalent. Ultimately, the goal of this research is to explore whether or not a direct relationship exists between fission density and the fuel microstructure in relation to fission gas bubble nucleation and growth.

It is also important to consider the statistical reliability of the image processing parameters used to compare between samples. A small sensitivity analysis was performed to determine the parameter best suited for the prediction of fission density. For spatial statistics, the fission bubble area, equivalent diameter, major axis length, minor axis length, convex area, and bounding box were all considered. The equivalent diameter was determined to possess the lowest 
relative standard deviation among the options, so it was selected as the primary means of comparison. For morphology statistics that are independent of feature size, eccentricity, circularity, form factor, and aspect ratio were considered. The eccentricity measurement provided the most consistent results across similar images, and was therefore selected as the primary morphological statistic.

Finally, it is worth mentioning the reliability and repeatability of the algorithm with respect to human input. Due to the variant nature of the images, the image processing parameters must change between samples in order to achieve the best results. In an ideal scenario, all of the parameters would be automatically determined using local image statistics, eliminating any subjective decisions from the user. Such a system may be implemented for the sake of consistency, but it often does not result in the best segmentations. The limited contrast between many of the fission bubbles and the fuel matrix results in histograms that have no discernible classes. As a result, automated threshold calculations may vary from image to image more than subjective thresholds. Furthermore, a threshold value represents only one of the many processing parameters. Therefore, a user is presented with a set of default values and a procedure for tuning the algorithm to a sample image for optimal segmentation. A single set of inputs is then used to segment the entire sample image stack. For the five samples analyzed in this work, parameter values remained static for samples originating from the same fuel plate.

\section{RESULTS}

Using the image-processing algorithm previously discussed, two-dimensional data was extracted from the binary images for each fuel sample. Table 3 summarizes the mean results for each of the primary feature parameters. In Figure 5, the size distributions obtained for all five samples are normalized and plotted against each other in terms of equivalent diameter. The size 
Table 3: Summary data for all U-7wt\%Mo five dispersion fuel samples.

\begin{tabular}{cccccc}
\hline & $\begin{array}{c}\text { Fission } \\
\text { Density }\left(10^{21}\right. \\
\left.\text { fissions } / \mathrm{cm}^{3}\right)\end{array}$ & $\begin{array}{c}\text { Porous } \\
\text { Volume } \\
\text { Fraction }(\%)\end{array}$ & $\begin{array}{c}\text { Mean Pore } \\
\text { Equivalent } \\
\text { Diameter }(\mu \mathrm{m})\end{array}$ & $\begin{array}{c}\text { Mean Pore } \\
\text { Area }\left(\mu \mathrm{m}^{2}\right)\end{array}$ & $\begin{array}{c}\text { Mean } \\
\text { Eccentricity }\end{array}$ \\
\hline A & 5.2 & 12.485 & 0.164 & 0.040 & 0.651 \\
B & 5.2 & 11.331 & 0.173 & 0.036 & 0.698 \\
C & 5.5 & 7.684 & 0.118 & 0.016 & 0.745 \\
D & 5.5 & 7.482 & 0.116 & 0.015 & 0.736 \\
E & 6.3 & 18.418 & 0.323 & 0.112 & 0.690 \\
\hline
\end{tabular}

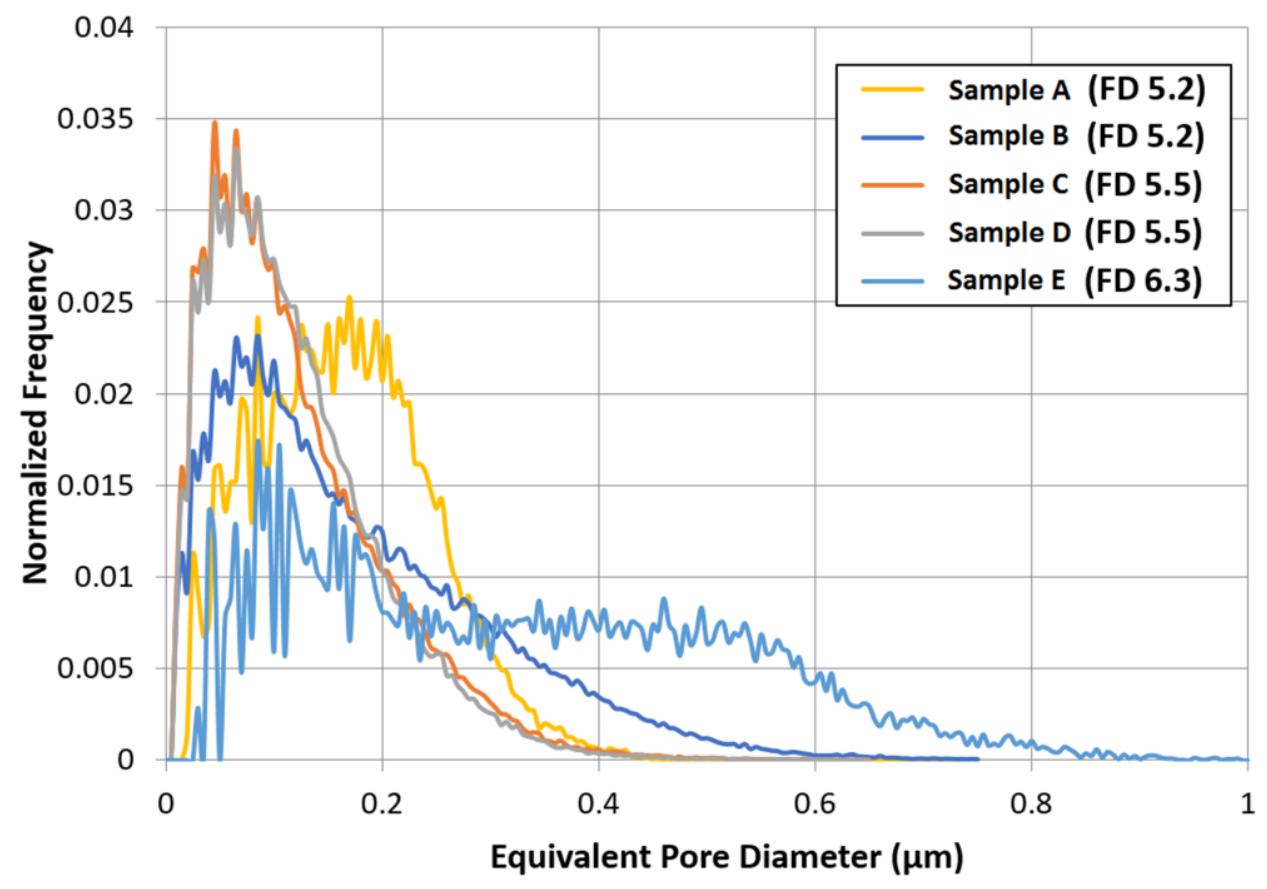

Figure 5: Fission gas bubble size distribution for all five samples.

distribution is a key metric used for identifying fission gas trends both within and between different fuel plates. The two samples from the R9R010 fuel plate (C and D) exhibit nearly identical porosity size distributions, while the two samples from the R3R050 plate (A and B) possess similar size frequencies but variant diameters. The lone R2R040 fuel plate sample (E) shows a much wider span of fission bubble sizes, including pores with significantly larger diameters than the lower fission density samples. 
Figure 6 presents the morphology distributions of each sample using the eccentricity calculation. Only sample A shows a morphology distribution that deviates from the other samples. The increased percentage of circular pores in A is unexpected considering it experienced a lower estimated fission density. However, the eccentricity distribution is within a margin of error that could have been caused as a consequence of the lower image resolution available in the sample A images. The lower resolution makes it more difficult for the imageprocessing algorithm to resolve the feature edges.

Figure 7 plots the $10^{\text {th }}, 50^{\text {th }}$, and $90^{\text {th }}$ percentiles of each size distribution in order to better visualize the data as it relates to the simulated fission density. Figure 8 shows the volume fraction and the mean area of the pores as compared to the fission density. Figure 7 and Figure 8 present a similar trend in the data. The mean pore diameter, area, and per slice volume fractions all decline between the $5.2 \times 10^{21}$ (A and B) and $5.5 \times 10^{21}$ fissions $/ \mathrm{cm}^{3}(\mathrm{C}$ and $\mathrm{D})$ samples

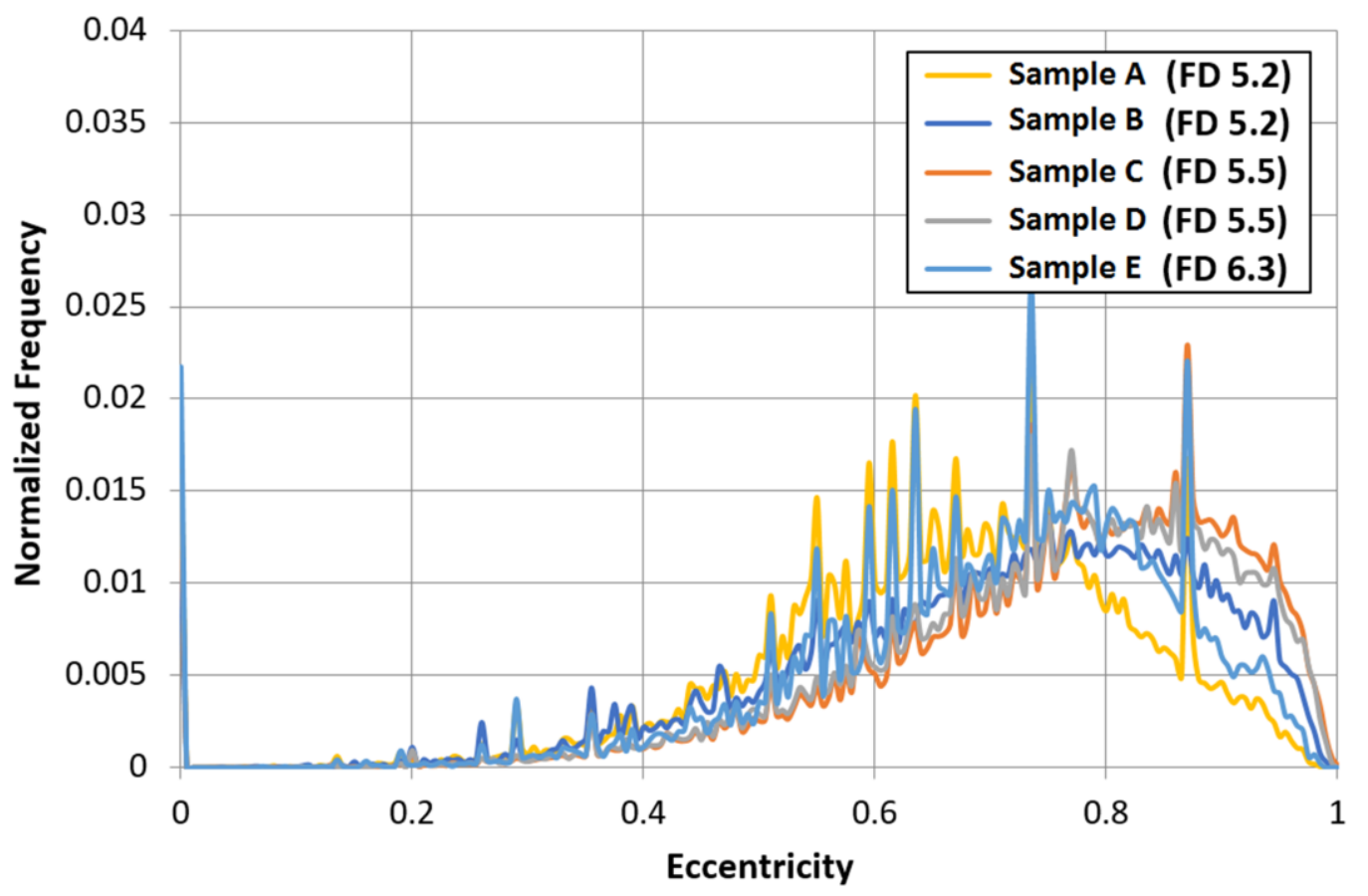

Figure 6: Eccentricity distributions for all five samples. 


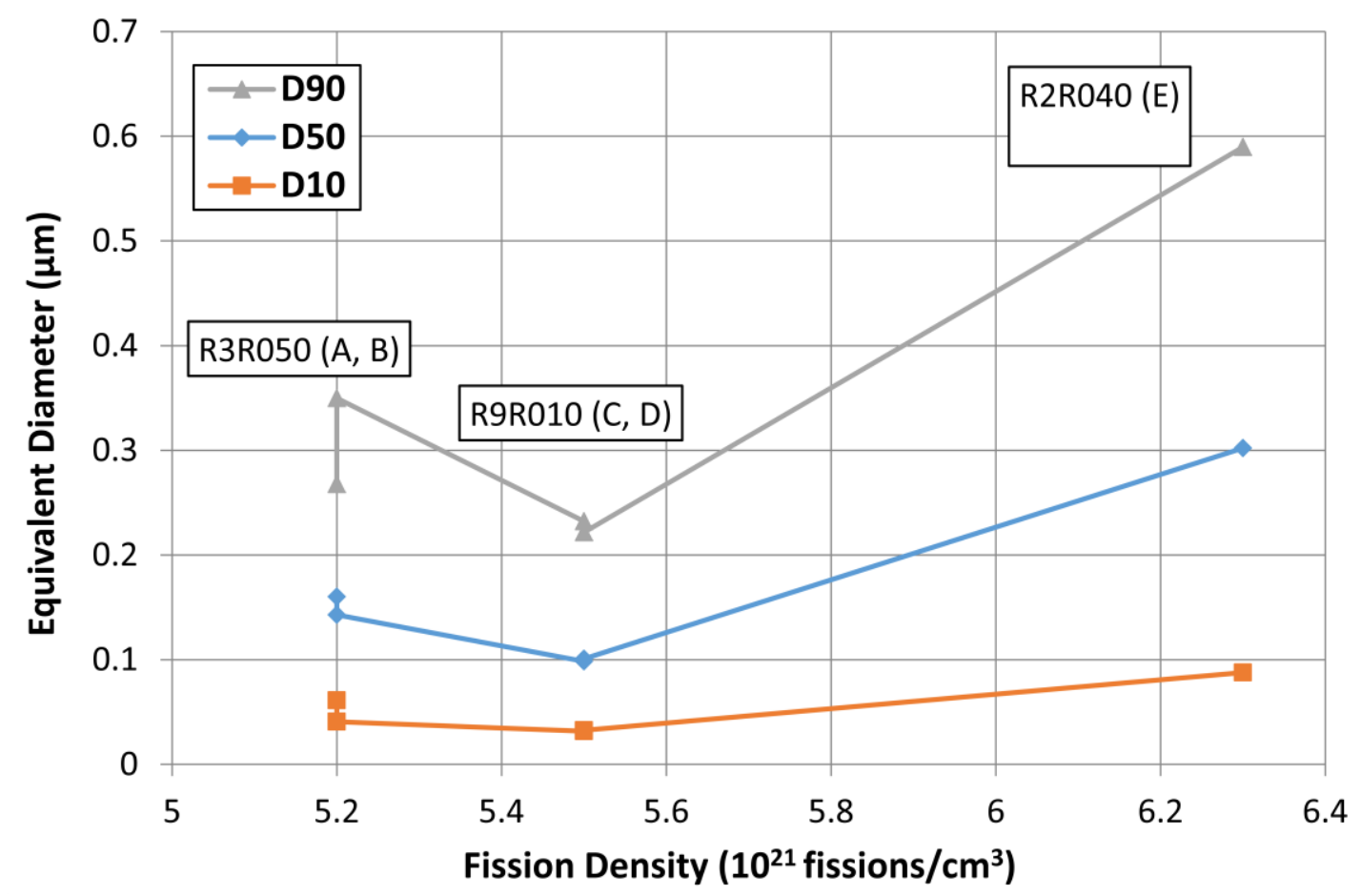

Figure 7: Comparison of $10^{\text {th }}, 50^{\text {th }}$ and $90^{\text {th }}$ percentile of fission gas bubble equivalent diameters for all five samples.

before increasing considerably in the $6.3 \times 10^{21}$ fissions $/ \mathrm{cm}^{3}$ (E) sample. This contradicts the assumption that fission gas pore size and fission density are linearly dependent. However, there may be additional variables that explain this phenomenon that will be discussed in the next discussion section.

Figure 9 shows a three-dimensional (3-D) reconstruction of sample B that was created using the Avizo software package. The software stacks the slices sequentially and interpolates based on the slice thickness. The added value of 3-D reconstruction is the potential to observe the interconnection of porosity, which is a sign of breakaway swelling. Figure 10 presents two sub-volumes of sample B. Figure 10a illustrates the pore morphology directly adjacent to a residual grain boundary, while Figure 10b illustrates the pore morphology away from any grains boundaries. 


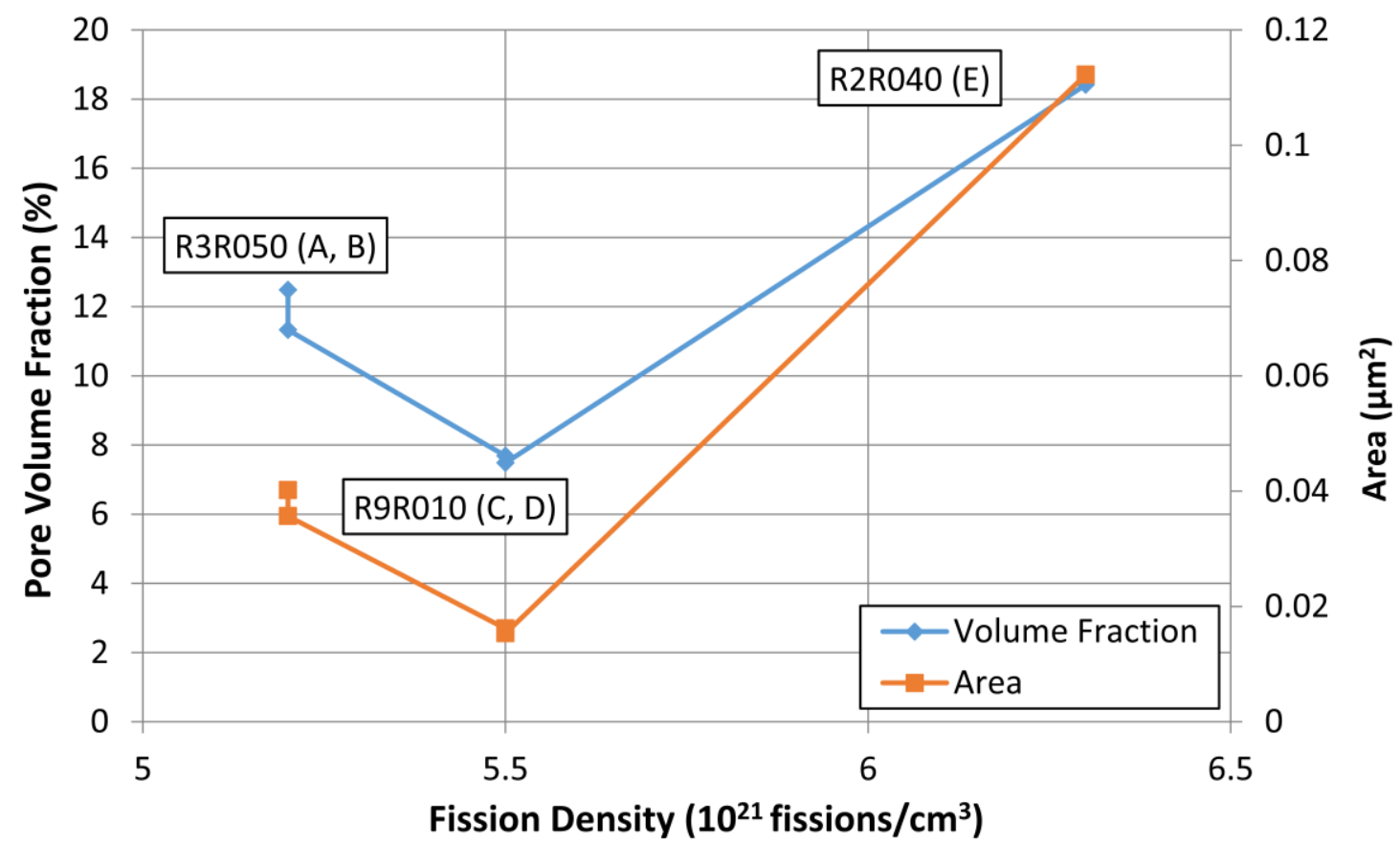

Figure 8: Porosity and area determinations for all five samples arranged by local fission density.

\section{DISCUSSION}

As mentioned previously, Figure 5 shows highly similar fission bubble size distributions for the two samples (C and D) from the R9R010 fuel plate. Such behavior is expected for dispersed homogeneous fuel particles that undergo similar fission densities. This indicates that the two separate fuel particles behaved similarly during irradiation and validates the homogeneity and consistency associated with the two sampling locations. Samples A and B, on the other hand, demonstrate more variant distributions. Sample A had a $10^{\text {th }}$ percentile pore diameter of $0.061 \mu \mathrm{m}$ and a $90^{\text {th }}$ percentile diameter of $0.268 \mu \mathrm{m}$. Compared to sample $\mathrm{B}$, which had a $10^{\text {th }}$ percentile diameter of $0.041 \mu \mathrm{m}$ and a $90^{\text {th }}$ percentile diameter of $0.351 \mu \mathrm{m}$, it is evident that sample A has a much tighter distribution of pore sizes; fewer smaller pores as well as fewer larger pores. This phenomenon can likely be attributed to two factors. The first is the lower resolution (taken at 8500x magnification) of the sample A images. An inability to resolve 


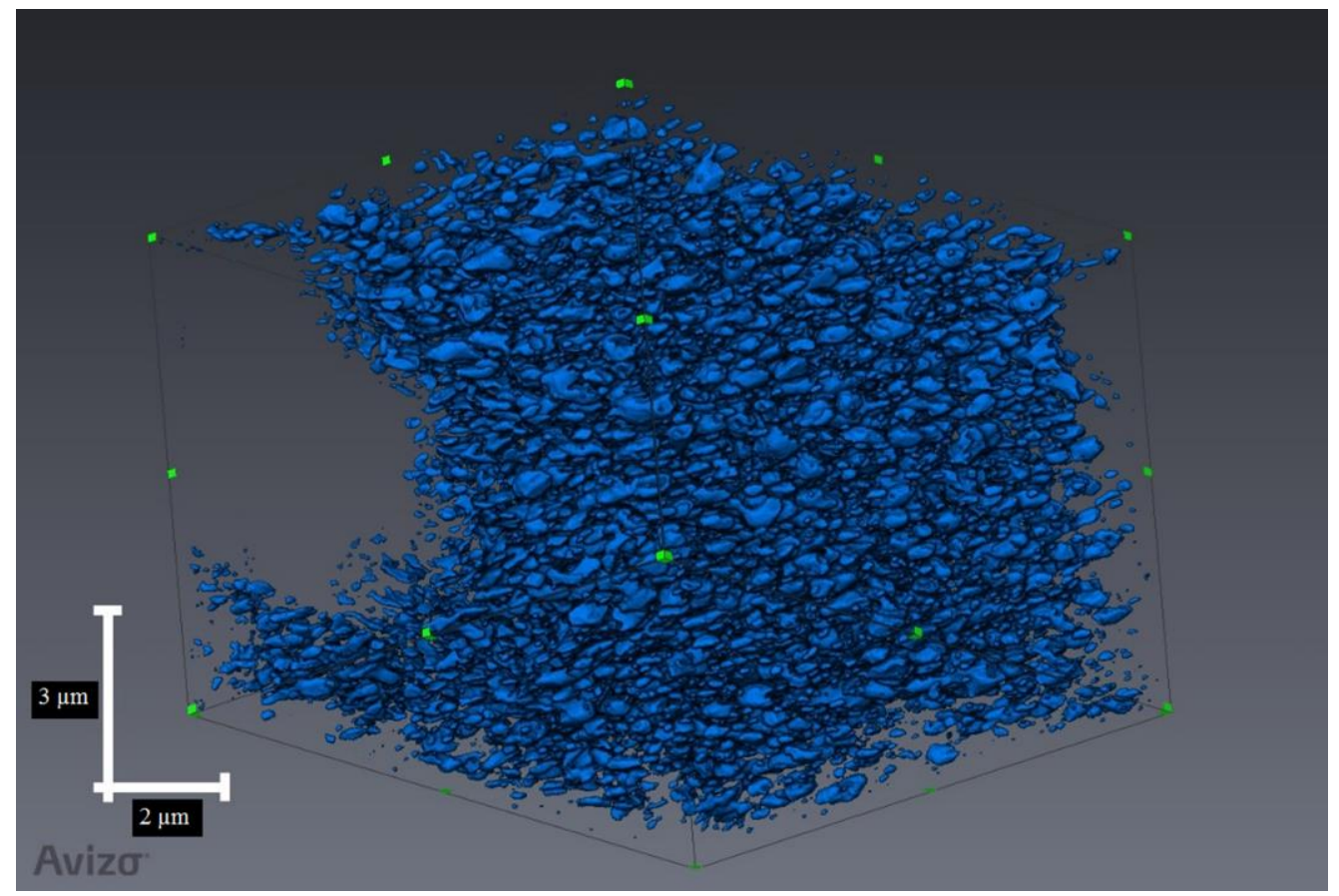

Figure 9: 3-D reconstruction of sample B.

the small diameter pores may explain the lack of information on the lower end of the distribution. The second potential explanation is the inconsistency in fuel homogeneity between sampling locations. The computer code used to calculate irradiation conditions assumes all of the fuel particles are loaded into the matrix homogenously and therefore does not account for touching particles. As a result, if the location a fuel sample is directly adjacent to a separate fuel particle, that sample may have experienced a higher fission density than what was calculated by the computer code. An increased fission density could explain the existence of the larger diameter pores observed in sample B.

When comparing data across samples from different fuel plates, it is challenging to identify any dominant trends. Figure 7 and Figure 8 show a decrease in value for the intermediate fission density sample (Samples C and D) with respect to pore equivalent diameter, volume fraction, and area. Existing knowledge of nuclear fuel microstructures indicates that as fission density increases, so should the porosity of the affected region. This trend is clear when 


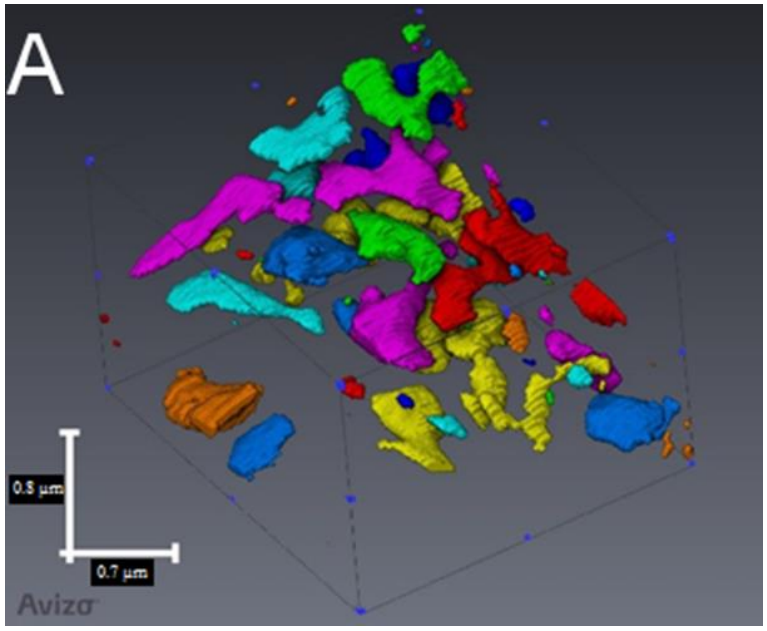

a) Fission bubbles adjacent to residual grains.

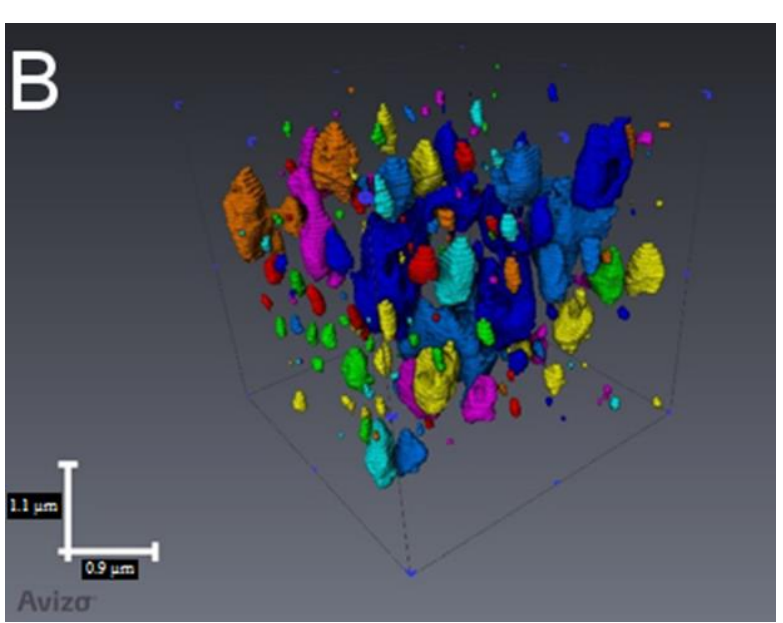

b) Fission bubbles away from grain boundaries.

Figure 9: 3-D reconstructed sub-volumes of sample B.

comparing the data from plates R2R040 and R3R050 (RERTR-7). The simplest explanation for the R9R010 (RERTR-8) data set is the fact that this dispersion fuel had magnesium as the matrix, not aluminum or an aluminum-silicon alloy. It has been reported that magnesium is inert with respect to U-Mo, producing no fuel metal interaction and providing mechanical constraint around fuel particles, which limits the growth of fission gas bubbles (Keiser et al., Submitted). Aluminum and aluminum-silicon do not provide the same mechanical integrity because they chemically interact during fabrication and irradiation with the U-Mo fuel particles to form an amorphous interaction layer around the fuel particles that exhibits plastic flow (i.e., low viscosity and "fluid-like" behavior) and therefore less restriction on the fuel particle (Kim and Hofman, 2012). For magnesium matrix fuel samples, the matrix material may have a significant effect on the stresses observed by the fission gases. This logic coincides with the microstructures seen throughout the sample C and D FIB cubes. Grains that have not yet undergone recrystallization are abundant throughout the sample. The intact grains range from $2-5 \mu \mathrm{m}$ in diameter and persist for as many as 60 consecutive images $(\sim 3 \mu \mathrm{m})$. Residual grains also exist in the lowest fission 
density sample, B, but with far less frequency. In fact, there are only three micron sized intact grains in the entire image stack, one of which (shown in Figure 4), is over $7 \mu \mathrm{m}$ in diameter and continues throughout the entire sample $(10 \mu \mathrm{m})$. The size of this uncrystallized region compared to the others may just be a pro duct of random variance, but it is impossible to overlook the increased frequency of uncrystallized regions in the higher burn-up, magnesium matrix samples (C and D). These results may indicate that the magnesium matrix fuel imparts more stress on the fuel particles than its aluminum counterpart by effectively restricting the swelling that occurs as a consequence of recrystallization. A similar effect of mechanical restriction on the fuel particle has been reported for rod-type U-Mo dispersion fuel, where the geometry reportedly compresses the U-Mo fuel particles and matrix such that pore formation is delayed and the fission gas bubble growth in the U-Mo fuel particles is lower (Kim et al., 2015). In addition, the starting microstructure of these samples was likely different due to the various fabrication processes associated with the application of the matrix material and this could impact fission gas bubble morphology. With respect to irradiation temperature, the U-7Mo fuel particles in the aluminum and aluminum-silicon matrix samples may have experienced higher temperatures compared to the magnesium matrix sample, due to the growth of the interaction layer, which is a low thermal conductivity phase (Kim, 2012). Higher temperatures can result in faster kinetics for fission gas mobility and ultimately larger fission gas bubbles. By comparison, magnesium has a noticeably lower thermal conductivity than aluminum as demonstrated by a recent simulation (Piro and Leitch, 2014).

The eccentricity distributions (Figure 6) indicate a larger departure from circular pores for sample C and D than observed in samples A, B and E. This is another indicator that perhaps the magnesium matrix dispersion fuel results in a more mechanically stable morphological 
evolution under increased fission densities than the aluminum matrix fuels. The A sample demonstrated the most circular (closest to 0) pores, but this is more likely a result of the sample image resolution than being realistic. It is worth nothing that a high eccentricity (approaching 1) does not necessarily indicate a lack of symmetry on account of the jagged nature of the feature boundaries. Outside of sample A, sample E (the $6.3 \times 10^{21}$ fissions $/ \mathrm{cm}^{3}$ fission density sample) was calculated to have the most eccentric pores. Due to the fuel's crystalline structure, the gas bubbles are expected to be non-spherical. However, transmission electron microscopy results have shown that there is an amorphous region around the bubbles (Gan et al., 2012). This phenomenon may allow the unconfined gasses to trend toward a spherical configuration. In general, the morphology results demonstrate that bubbles are highly irregular. The eccentricity values support the theory that the development of large bubbles in the fuel grain interior is driven by the coalescence of fine bubbles collapsed from the fission gas bubble superlattice. The irregular shape of the bubbles as a result of bubble coalescence highlights the complex interaction of the bubble evolution with its surrounding fuel material and solid fission products (Gan et al., 2014).

The one morphological pattern that can be observed in these microstructures is the impact of residual fuel grains that is illustrated in Figure 4. While large grains (such as in Figure 4) were cropped out of the dataset, it proved impractical to remove all of the smaller grains in several of the samples. Sample C and D in particular contain grains in every region of the image set. The presence of these residual grains results in flattened and elongated gas pores. The inclusion of these pores in the binary data set shifts the eccentricity results closer to 1 (non-circular). The average morphology of the gas bubbles (Table 3) supports this reasoning, as sample $\mathrm{C}$ and sample D show eccentricities closer to 1 than samples A, B, or E. 
Given the results, it would be inappropriate to fit a fission density to porosity correlation to just the three samples from the RERTR-7 test. However, the data points can be used to compare with previously established literature. In independent Russian experiments on U9.4wt \% Mo dispersion fuel particles, a steady rise in sample porosity has been observed followed by a sharp incline up to around $4.2 \times 10^{21}$ fissions $/ \mathrm{cm}^{3}$ (Izhutov et al, 2011). The correlation equation that fits the experimental values obtained by the Russian RERTR program is plotted in Figure 11. The porosity results from the aluminum matrix samples (A, B, and E) are also included in Figure 11 for comparison purposes. This report only includes high burnup samples, so no conclusions can be drawn as to the behavior prior to the recrystallization (critical) fission density. The $5.2 \times 10^{21}$ fissions $/ \mathrm{cm}^{3}$ samples (A and B) show acceptable agreement with the Izhutov porosity correlation, falling within $1-2 \%$ porosity. Sample E is nearly $4.5 \%$ more porous than the correlation predicts. A potential explanation for this discrepancy is the $9.4 \mathrm{wt} \%$

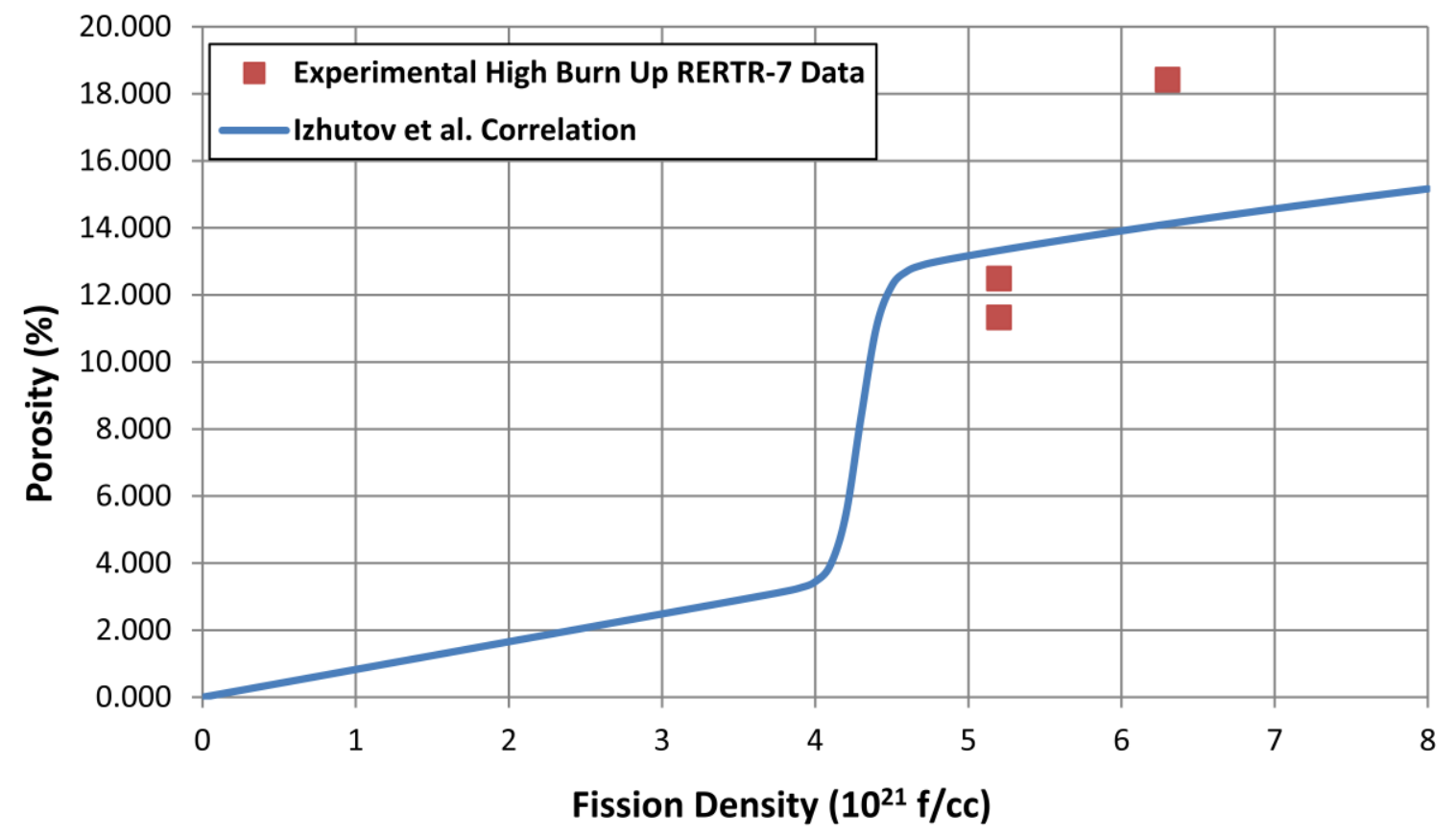

Figure 10: Sample A, B and E FIB cube porosity results compared to results obtained by the Russian conversion program. 
molybdenum content in the Russian samples as compared to the $7 \mathrm{wt} \%$ molybdenum INL samples. Increased molybdenum content has been shown to allow the fuel to reach higher fission densities prior to the transition to high burnup microstructure (Keiser et al., 2014). This suggests the Russian samples may have had a lower porosity at similar fission densities. In addition, the Russian tests were performed using U-Mo dispersion rods instead of plates (Izhuvtov et al., 2011). Dissimilar fuel formations result in different stress contraints on the fuel kernels and therefore different microstructures. This may be another explanation for the disparity from the correlation.

In European experiments with U-7wt\%Mo alloy particles dispersed in a pure aluminum matrix, the fission density to porosity results relate more closely to those found in this study. At the highest fission density observed in the European experiments, $5.2 \times 10^{21}$ fissions $/ \mathrm{cm}^{3}$, porosities ranging from 12 to $15 \%$ were calculated (Leenaers, 2014). Based on the data, it seems likely that the European experimental porosity would have continued to increase above the porosity predicted by Izhutov's correlation if tests of higher fission densities were performed. This may indicate that the trend isn't applicable across fuels with varying molydenum content, but more testing is needed to reach any definitive conclusions. Another concern is the standardization between porosity determination methods. The development of the image processing procedure to determine porosity for this study highlighted how easy it is to produce varying porosity measurements. Factors such as the inclusion of solid fission products and residual grains, segmentation errors, or grid counting bias all have the potential to skew the results from the true porosity.

Ultimately, for the purposes of comparing fission densities to porosity in samples, destructive milling to create individual images is more practical than preparing FIB cubes. Serial 
section data produces a marginally more accurate estimation of porosity because it incorporates the fluctuations in fission bubble packing into the average. However, the slice-to-slice porosity standard deviations are typically less than $0.75 \%$ so it isn't necessary. Individual images could provide a similar result and it is worth considering if the cost and limited availability of the FIB outweighs the improved accuracy. A larger sample size would be more beneficial than a few high fidelity data points. The real value of the serial sectioned FIB cubes is the ability to observe the microstructures in three-dimensions. The interconnection of porosity is a key feature that can be observed in a 3-D reconstruction. Interlinking porosity is the primary factor responsible for breakaway swelling. In time, the pores can become large enough to form a blister and rupture, resulting in the release of fission products. The wider size distribution of the highest fission density sample (Figure 5, Series A) is an indicator that some of the pores are interlinking.

The 3-D reconstructions on the samples in this study confirm the 2-D data. While the 2-D data already reveals that the spatial variation within the fuel plate for a length of about $15 \mu \mathrm{m}$ has no large impact in terms of pore size and porosity, 3-D data shows that there is no obvious anisotropy in the direction orthogonal to the slices and the pores typically show a faceted spherical shape. From the pore volume distribution, it can also be concluded that the pores are more frequently isolated than they are interlinked. The isolation characteristic can also be seen in Figure . However, there are instances of interlinking that can be observed in all of the samples, with increasing frequency as fission density increases. This supports the notion that higher fission densities will eventually lead to breakaway swelling and fission gas tunneling. That being said, these results indicate the fission gas is still well contained within the fuel meat at fission densities up to $6.3 \times 10^{21}$ fissions $/ \mathrm{cm}^{3}$. 
Adjacent to remaining grains, the 3-D reconstruction of the fission gas pores show the varying morphology and connectivity. In 2-D, it can be seen that the pore diameter is smaller at the grain boundaries when compared to the bulk of the pores. This occurrence is readily apparent when observing the pores in 3-D. The connectivity and elongation of these pores (shown in Figure 10a) indicates higher stresses in the fuel in these locations than in the crystallized zones (shown in Figure 10b).

In order to fully understand the effects of irradiation conditions on the fission gas pore distribution, it is suggested that future samples be harvested from a plate that was subjected to a gradient in fission density. This would resolve the composition and fabrication standardization issues experienced in this study and provide a range of samples representative of only the local irradiation parameters. It would also fill out the correlation data points to include fission

densities below the critical $4.5 \times 10^{21}$ fissions $/ \mathrm{cm}^{3}$ threshold. Once the relationship between fission density and fission gas microstructures is well established, samples with different compositions and fabrication techniques can then be compared to observe the effects of introducing additional variables.

\section{CONCLUSIONS}

Fission gas pore segmentation was performed on fuel samples cotaining U-7wt\% Mo fuel particles dispersed in aluminum and magnesium matrices at three separate fission densities. Pore size distributions were attained that showed both expected and unexpected fission gas behavior. Samples with similar fission densities were demonstrated to have similar pore distributions, although samples from touching fuel particles were shown to have an altered pore microstructure as reflected by their increased size and frequency. It proved difficult to compare porosity distributions between samples with varying fabrication processes and irradiation parameters. The 
smaller pore size and porosity from the two R9R010 mini-plate samples (C and D) fabricated with a magnesium matrix may indicate that the magnesium matrix imparts more stress on the fuel particles. This increased stress results in a delay in the fission-induced recrystallization compared to the aluminum or aluminum-silicon matrix samples, and this can potentially reduce the overall fuel plate swelling. When the measured porosity as a function of fission density is compared for different samples with aluminum or aluminum-silicon matrices to those reported by Russian researchers, fair agreement is observed. It is recommended that future studies include a set of samples harvested in serial from a fuel plate subjected to a gradient of fission densities. This will standardize the variables in play and help to pinpoint the driving mechanism behind fission gas pore nucleation and growth.

\section{ACKNOWLEDGEMENTS}

This work was supported by the U.S. Department of Energy, Office of Material Management and Minimization, National Nuclear Security Administration, under DOE-NE Idaho Operations Office Contract DE-AC07-05ID14517. This manuscript was authored by a contractor for the U.S. Government. The publisher, by accepting the article for publication, acknowledges that the U.S. Government retains a nonexclusive, paid-up, irrevocable, worldwide license to publish or reproduce the published form of this manuscript, or allow others to do so, for U.S. Government purposes.

\section{U. S. Department of Energy Disclaimer}

This information was prepared as an account of work sponsored by an agency of the U.S. Government. Neither the U.S. Government nor any agency thereof, nor any of their employees, makes any warranty, express or implied, or assumes any legal liability or responsibility for the accuracy, completeness, or usefulness of any information, apparatus, product, or process 
disclosed, or represents that its use would not infringe privately owned rights. References herein to any specific commercial product, process, or service by trade name, trademark, manufacturer, or otherwise, does not necessarily constitute or imply its endorsement, recommendation, or favoring by the U.S. Government or any agency thereof. The views and opinions of authors expressed herein do not necessarily state or reflect those of the U.S. Government or any agency thereof. 


\section{REFERENCES}

American Society for Testing and Materials, Standard Test Method for Determining Volume Fraction by Systematic Manual Point Count, ASTM International, E562-11, West Conshohocken, PA, 2011, doi: 10.1520/E0562-11.

Collette R., King J., Keiser JR. D., Schulthess J., "Fission Gas Bubble Identification using MATLAB's Image Processing Toolbox," Materials Characterization, IN REVIEW.

Ding S., Huo Y., Yan X., "Modeling of the heat transfer performance of plate-type dispersion nuclear fuel elements," Journal of Nuclear Materials, 2009, vol. 392, pp. 498-504, doi: 10.1016/j.jnucmat.2009.04.015

Gan J., Miller B. D., Keiser Jr. D. D., Robinson A. B., Medvedev P., Wachs D. M., "Microstructural characterization of irradiated U-7Mo/Al-5Si dispersion fuel irradiated to high fission density," Journal of Nuclear Materials, 2014, vol. 454, pp. 434-445, doi: 10.1016/j.jnucmat.2014.08.052.

Gan J., Keiser Jr. D. D., Miller B. D., Robinson A. B., Medvedev P., Wachs D. M., "TEM characterization of U-7Mo/Al-2Si dispersion fuel irradiated to intermediate and high fission densities," Journal of Nuclear Materials, 2012, vol. 424, pp. 43-50, doi: 10.1016/j.jnucmat.2012.02.001.

Gonzalez R.C., Woods R.E. Digital Image Processing. 3rd ed., Pearson - Prentice Hall, Upper Saddle River, New Jersey, 2008.

Izhutov A. L., Iakovlev V.V., Kosenkov V.M., Novoselov A.Y., Starkov V.A., Sheldyakov A.A., Shishin V. Y., Dobrikova I.V., Kulakov G.V., Vatulin A.V., Suprun V.B., "Comparative Analysis of Structural Changes in the U-Mo Dispersed Fuel of Full-Size Fuel Elements and Mini-Rods Irradiated in the MIR Rector," Nuclear Engineering and Technology, 2013, vol. 45, pp 859-970, doi: 10.5516/NET.07.2013.716

Keiser Jr. D. D., Jue J. F., Robison A. Medvedev B. P., Gan J., Miller B. D., Wachs D. M., Moore G. A., Clark C. R., Meyer M. K., Finlay M. R., "Effects of Irradiation on the Microstructure of U-7Mo Dispersion Fuel with Al-2Si Matrix", Journal of Nuclear Materials, 2012, vol. 425, pp. 156-172, doi: 10.1016/j.jnucmat.2012.01.013.

Keiser Jr. D.D., Jue J.F., Miller B., Robinson A., Gan J., Williams W., Medvedev P., Wachs D., "SEM and TEM Characterization of U-7Mo Irradiation to High Fission Density at Relatively High Power, High Temperature, and High Fission Rate," Proceedings of 
International Meeting on Reduced Enrichment for Research and Test Reactors (RERTR 2014), Vienna International Center, Vienna, Austria, 2014, paper S7-P3.

Keiser Jr. D. D., Miller B. D., Jue J. F., Gan J., Robinson A.B., Medvedev P., Madden J., Teague M., Wachs D.M., "SEM Charaterization of the High Burn-Up Microstructure of U-7Mo Alloy," Proceedings of Research Reactor Fuel Management Conference (RRFM), Ljubljana, Slovenia, 2014.

Keiser, Jr. D.D., Jue J. F., Miller B.D., Gan J., Robinson A.B., Medvedev P.G., Madden J.W., Moore G.A., "Microstructural Characterization of a Mg Matrix U-Mo Dispersion Fuel Plate Irradiated in the Advanced Test Reactor to High Fission Density: SEM Results," Metallurgical and Materials Transactions E, submitted for publication.

Kim Y.S., "Uranium Intermetallic Fuels (U-Al, U-Si, U-Mo)," In: Konings R.J.M. (ed.) Comprehensive Nuclear Materials, 2012, vol. 3, pp. 391-422, Amsterdam: Elsevier.

Kim Y.S., Park J.M., Ryu H.J., Jung Y.H., Hofman G.L., "Reduced interaction layer growth of U-Mo dispersion in Al-Si," Journal of Nuclear Materials, 2012, vol. 430, pp. 50-57, doi: 10.1016/j.jnucmat.2012.06.032.

Kim Y.S., Hofman G.L., "Irradiation Behavior of the Interaction Product of U-Mo Fuel Particle Dispersion in an Al Matrix," Journal of Nuclear Materials, 2012, vol. 425, pp. 181-187, doi: $10.1016 /$ j.jnucmat.2011.07.032.

Leenaers, A., "Surface-engineered Low-enriched Uranium-Molybdenum Fuel for Research Reactors," PhD Dissertation, University of Ghent, Department of Solid State Science, 2014, Ghent, Belgium.

MathWorks, Inc., MATLAB and Image Processing Toolbox Release 2013a, Natick, Massachusetts, December 2014.

Meyer M.K., Gan J., Jue J.F., Keiser D.D., Perez E., Robinson A., Wachs D.M., Woolstenhulme N., Hofman G.L., Kim Y.S., "Irradiation Performance of U-Mo Monolithic Fuel," Nuclear Engineering and Technology, 2014, vol 46., pp. 169-182, doi: $\underline{10.5516 / N E T .07 .2014 .706 . ~}$

Miller B.D., Gan J., Madden J., Jue J.F., Robinson A., Keiser Jr. D.D. "Advantages and disadvantages of using a focused ion beam to prepare TEM samples from irradiated U10Mo monolithic nuclear fuel," Journal of Nuclear Materials, 2012, vol. 424 , pp. 38-42, doi: 10.1016/j.jnucmat.2012.01.022.

Perez D.M., Lillo M.A., Chang G.S., Roth G. A., Woolstenhulme N. E., Wachs D. M., "RERTR-7 Irradiation Summary Report", Idaho National Laboratory Technical Report INL/EXT-11-24283, Idaho Falls, Idaho, December 2011.

Perez D.M., Lillo M.A., Chang G.S., Roth G. A., Woolstenhulme N. E., Wachs D. M., "RERTR-8 Irradiation Summary Report", Idaho National Laboratory Technical Report INL/EXT-11-24284, Idaho Falls, Idaho, December 2011. 
Piro M.H.A., Leitch B.W., "Conjugate heat transfer simulations of advanced research reactor fuel," Nuclear Engineering and Design, 2014, vol. 274, pp. 30-43, doi: 10.1016/j.nucengdes.2014.03.054

Robinson A.B., Chang G.S., Keiser, D.D. Jr., Wachs D.M., Porter D.L., "Irradiation Performance of U-Mo Alloy Based 'Monolithic' Plate-Type Fuel - Design Selection," Idaho National Laboratory Technical Report INL/EXT-09-16807, Idaho Falls, Idaho, August 2009.

Sauvola J., Pietikainen M., “Adaptive document image binarization,” Pattern Recognition, 2000, vol. 33, pp 225-236, doi: 10.1016/S0031-3203(99)00055-2.

Tomasi C., Manduchi R. "Bilateral Filtering for Gray and Color Images," Proceedings of the IEEE International Conference on Computer Vision, Bombay, India, 1998.

Wachs, D.M., "RERTR Fuel Development and Qualification Plan," Idaho National Laboratory Technical Report INL/EXT-05-01017 Rev. 3, Idaho Falls, Idaho, January 2007. 


\section{Graphical Abstract}

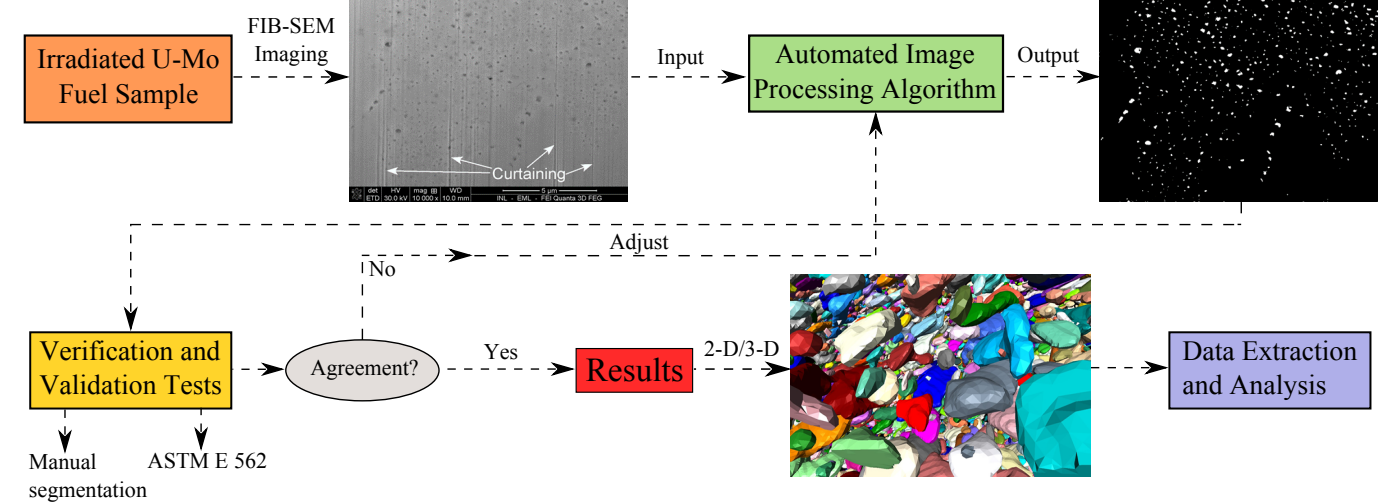

